\title{
AUGUSTUS
}

\section{O ENIGMA DA PANDEMIA DO COVID-19: SOLIDARIEDADE, FORMAÇÃO HUMANA E CIDADANIA EM TEMPOS DIFÍCEIS}

\author{
Luís Carlos Ferreira \\ Universidade da Integração Internacional da Lusofonia Afro-brasileira - UNILAB \\ luisferreira@unilab.edu.br \\ Cláudia de Freitas Lopes Costa \\ Centro Universitário Augusto Motta - UNISUAM \\ claudiacosta@unisuam.edu.br \\ Júlia Tadeu Silva dos Santos e Paula \\ Centro Universitário Augusto Motta - UNISUAM \\ juliaspaula@souunisuam.com.br
}

\begin{abstract}
RESUMO
O convite para essa escrita feita a muitas mãos, já começa inédita por vários motivos: por se tratar de um texto científico-acadêmico não apresentado ainda e, por ser uma temática com tão pouca ou nenhuma literatura [nesse momento], com abordagem que não seja na área da saúde. Dessa forma, a ideia do texto é simples: refletir sobre o enigma do surto da pandemia da COVID-19 no mundo, na perspectiva da solidariedade, formação humana e cidadania, e seus efeitos [generalizados] no presente e no futuro imediato. Metodologicamente, a pesquisa qualitativa, do tipo bibliográfica; está debruçada em fontes e referências como: Harvey, Giddens, Frigotto, Freire, Boaventura e alguns outros. Assim, a análise pautada nas metamorfoses do capital e da vida humana, entre os "velhos" e "novos" aspectos que, de um lado, influenciaram no aumento da desigualdade e das ameaças à natureza humana e nas prospecções de futuro; e de outro lado, nos permitiram refletir sobre os novos cenários na produção da solidariedade, da formação de valores humanos e, por fim, da cidadania. E por fim, esperamos [como resultado] que a dura trajetória da crise sanitária do coronavírus, sirva de aprendizado para revermos e refazermos ações, posturas, comportamentos, princípios e valores capazes de nos tornar melhores no começo de um novo tempo.
\end{abstract}

Palavras-Chave: COVID-19. Pandemia. Solidariedade. Formação humana. Cidadania.

\section{THE COVID-19 PANDEMIC ENIGMA: SOLIDARITY, HUMAN FORMATION AND CITIZENSHIP IN HARD TIMES}

\begin{abstract}
The invitation to this writing made by many hands, has already started unprecedented for several reasons: because it is a scientific-academic text not yet presented and, because it is a theme with so little or no literature [at that moment] with an approach that is not In the health area. Thus, the idea of the text is simple: reflect on the enigma of the outbreak of the COVID19 pandemic in the world, from the perspective of solidarity, human formation and citizenship, and its [generalized] effects in the present and the immediate future. Methodologically, qualitative research, of a bibliographic type, is focused on sources and references such as: Harvey, Giddens, Frigotto, Freire, Boaventura and some others. Thus, the
\end{abstract}


analysis based on the metamorphoses of capital and human life, among the "old" and "new" aspects that, on the one hand, influenced the increase in inequality and threats to human nature and the prospects for the future; on the other hand, they allowed us to reflect on the new scenarios in the production of solidarity, the formation of human values and, finally, citizenship. And finally, we hope [as a result] that the harsh trajectory of the coronavirus health crisis will serve as a learning tool for reviewing and redoing actions, attitudes, behaviors, principles and values capable of making us better at the beginning of a new era.

Keywords: COVID-19. Pandemic. Solidarity. Human formation. Citizenship. 


\section{INTRODUÇÃO}

“Não podemos voltar ao normal, porque o normal era exatamente o problema11" (Anônimo de Hong Kong).

Em tempos recentes, em que o mundo vive uma grande adversidade que marca o século XXI, podemos dizer que temos duas certezas: a primeira, de que o mundo parou; a segunda, de que se tornou inédito viver.

A tela branca do computador parece ser a forma simples de dizer que estamos diante de muitas certezas e incertezas, de cenários bem diferentes, de temores sobre o que nos aguarda mais adiante, mas, acima de tudo, de um porvir repleto de esperança. Esperança de um novo tempo, uma nova humanidade, uma nova forma de ver a vida, uma nova forma de educar o homem.

Metamorfose ou metamorfoses? Seja no singular e no plural, a interpretação do grafite deixado em um muro em Hong Kong, na China, utilizada como epígrafe no texto, mostra que não somos e nem seremos mais os mesmos!

Sendo assim, o convite para essa escrita feita a muitas mãos, já começa inédita por vários motivos: por se tratar de um texto científico-acadêmico não apresentado ainda e, por ser uma temática com tão pouca ou nenhuma literatura, nesse momento, e com abordagem que não é a da área da saúde. Dessa forma, nasce o compromisso de que, sozinhos, não conseguiremos sair desse cotidiano, enquanto "lugar comum", e não avançaremos em nossas questões individuais e coletivas.

Então, surge a necessidade de utilizarmos o pronome "nós", simbolicamente, como um significado de que estamos juntos em proximidade ou separados, fisicamente, mas conectados por redes tecnológicas e redes afetivas. Da mesma forma, carregamos a preocupação de somarmos esforços na busca por alternativas para o presente imediato e para o futuro, que nos tornem mais humanos e melhores em tempos tão difíceis.

\footnotetext{
${ }^{11}$ Grafite estampado em um muro em Hong Kong. (GRAFFITI..., 2020).
} 
Antes, é preciso dizer que o verbo no gerúndio ${ }^{12}$ é proposital. Embora seja pouco usual, em nosso texto, serve como um aliado para explicar o quão complexa e enigmática é a situação que vem acontecendo no mundo: a pandemia da COVID-1913.

Uma paralisia planetária e que, em graus e maneiras diferentes, ressoa através de expressões e termos nunca antes falados tantas vezes, como: quarentena; isolamento social; distanciamento social e "fique em casa" que, hoje, estão presentes no cotidiano atual de diversos povos, línguas e nações no mundo. Simultaneamente, os efeitos indiscriminados gerados por essas expressões revelam um misto de comportamentos, sensações e posturas, entre as quais destacamos o medo, a ansiedade, a cautela, a preocupação, a solidariedade. 0 mesmo vale para a mudança generalizada de hábitos como uso constante do álcool em gel e lavagem de mãos, uso de máscaras de proteção e outras medidas de segurança com a higiene.

Também se destacam a impossibilidade de muitos trabalhadores cumprirem as regras e orientações da Organização Mundial de Saúde (OMS) ou mesmo, comportamentos de resistência como a negação das regras de ficar em casa e evitar sair às ruas, abertura do comércio, aglomerações, entre tantos riscos de contágio do novo coronavírus, como é, também, conhecida a doença.

Sendo assim, a ideia é simples: refletir sobre o enigma do surto da pandemia da COVID-19 no mundo, na perspectiva da solidariedade, formação humana e cidadania, e seus efeitos generalizados no presente e futuro imediatos.

Longe de uma leitura romantizada, a perspectiva política de discutirmos questões tão sérias e que afligem toda a humanidade, faz-nos repensar os rumos de nossas próprias vidas.

\section{0 "VELHO" NA METAMORFOSE DO CAPITAL E DA VIDA HUMANA}

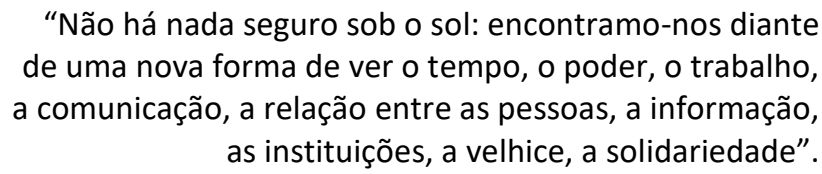

(IMBERNON, 2000, p. 19).

\footnotetext{
${ }^{12} \mathrm{O}$ verbo no gerúndio indica uma ação que ainda está em curso ou que é prolongada no tempo. Transmite, assim, uma noção de duração e continuidade de ação verbal. Disponível em: www.conjugacao.com.br/. Acesso em: 02 jun. 2020.

${ }^{13}$ Pela Fiocruz, a COVID significa Corona Vírus Disease ou, popularmente, conhecida como Doença do Coronavírus. Disponível em: www.portal.fiocruz.br. Acesso em: 02 jun. 2020.
} 
Passado esse período da pandemia causada pelo coronavírus, o mundo não será mais o mesmo! O que de "velho" e de "novo" ficam nessa transição ou na metamorfose do capital e da vida humana? Que significado ético, político e humano, dessa enfermidade disseminada entre os diferentes povos e sociedades, permanecerão entre nós? Que novas formas de educar - ensinar e aprender - iremos extrair diante de novos cenários que se apresentam?

Essas são algumas interrogações sem respostas concretas ainda, possivelmente, porque estamos no meio do surto no mundo e, ao mesmo tempo, na busca para compreendermos os impactos, os sentidos e os efeitos positivos ${ }^{14}$ do pós-COVID-19, na humanidade.

Diante do que temos e vivemos, a proposta incipiente de refletirmos sobre os tempos difíceis e as prospecções de futuro, nos permite pensar em novos cenários na produção da solidariedade, da formação de valores humanos e, por fim, da cidadania.

É preciso anteciparmos que a epígrafe de Francisco Imbernon nos dá mostras de que fomos surpreendidos por um balanço emergencial e, no extremo, uma paralisia em áreas estratégicas da sociedade - economia, política, saúde, cultura, educação e meio ambiente que entraram em colapso promovido, quem sabe, por uma crise do capitalismo real.

Debruçamo-nos em Harvey, Giddens, Frigotto, Boaventura e alguns outros, para discutirmos sobre a crise no paradigma atual da globalização, do capital, da crise ambiental e, não por acaso, dos valores humanos que perpassam as condições de cidadania. Dito de outra forma, as intensas transformações geradas pela globalização nos afetam de diversas formas, tanto para o bem como para o mal. Afinal, fomos confinados a uma propensa "tese de que agora vivemos todos em um único mundo". (Giddens, 2003, p. 18)

Não por acaso, podemos nos dirigir a um vírus também globalizado e que atravessou fronteiras de diversos países, espalhando essa terrível doença no mundo. Sem controle e sem a descoberta de tratamento ou vacina - até a presente escrita do texto - o vírus globalizado tem afetado a todos e em todas as áreas, sem falar no desenvolvimento social humano. No caso, a cura que ainda está por vir, tem mobilizado pesquisadores do mundo todo em prol de técnicas, estratégias de controle, tratamento e, principalmente, na descoberta de vacina.

\footnotetext{
${ }^{14}$ Os efeitos negativos já são conhecidos, à medida que temos acompanhado diariamente nas manchetes dos jornais e mídias sociais, as informações sobre o número de pessoas contaminadas e do grau de letalidade no mundo.
} 
Importa dizer que os efeitos das relações capitalistas, no contexto neoliberal, nos dão mostras da alienação, da intensificação na exploração, nas formas visíveis e invisíveis de exclusão, nos mecanismos de promoção da violência e, principalmente, da ampliação da desigualdade social e humana. Isso, para dizer que o coronavírus tem sua face mais perversa iniciada nas classes privilegiadas, quando disseminada no contato com pessoas que estiveram fora do país, chegando à classe trabalhadora ${ }^{15}$ e aos mais pobres e vulneráveis.

De um modo geral, a globalização adotada nas relações capitalistas tem promovido maior abertura de capital com a expansão, acumulação e aumento da riqueza concentrada nas instituições financeiras, nos mercados de capitais nacionais e estrangeiros, nas políticas de fronteiras e desenvolvimento geográfico, valendo-se do acesso tecnológico e comunicacional e, acima de tudo, na divisão social e técnica do trabalho. Ao mesmo tempo, herdamos o agravamento das desigualdades sociais, traduzido na falta de condições básicas de moradia, saneamento, no acesso às redes de proteção à saúde pública, na precarização crescente das relações de trabalho, nas desvantagens das políticas culturais e sociais e, não diferente, no acirramento da dualidade educacional.

Assistimos à pandemia que mais tem servido para agravar a situação de crise do capital ambiental e das relações humanas a que estamos sujeitos diretamente, enquanto população mundial, pelas questões econômicas e sociais, pois em termos de capital financeiro, o vírus invisível colocou em risco a economia do país e tem comprometido o crescimento financeiro e desenvolvimento do capital mundial de um lado; e do outro lado, abriu nossos olhos para a falta de condições aos cuidados essenciais e básicos da vida humana como acesso à água, saneamento básico, saúde pública, entre outras situações que comprometem a defesa da cidadania.

No diálogo com Frigotto (2007, p. 82) temos o seguinte: "os custos humanos, materializados pela fome, desemprego, desagregação social, erupções violentas e contínuas que se dão a nível planetário, são ética e politicamente inaceitáveis".

Embora não tenhamos como afirmar, a Organização Mundial de Saúde (OMS) e os estudos em andamento, não determinam que a COVID-19 teve origem em Wuhan, conhecida por ser um grande centro de produção para as economias globais, localizada na China ${ }^{16}$,

\footnotetext{
15 Lembrando que um dos primeiros casos revelados foi com uma empregada doméstica que teve contato com uma pessoa infectada.

${ }^{16}$ É bom lembrar que a China, recentemente, sofreu com os abalos da SARS, gripes aviária e suína.
} 
segundo maior centro econômico do mundo. Os sinais de início da crise, com fortes consequências para a dinâmica global no fluxo de capital, podiam ser esperados.

Contudo, a aposta nas consequências econômicas e os impactos locais do coronavírus eram de se esperar entre os países asiáticos. No entanto, o rápido deslocamento promovido nos mercados internacionais e redes de conexão com o mundo, gerados pelas "vantagens" da globalização, não conseguiram impedir os sinais dados pela forte queda da bolsa de valores com a difusão desse vírus entre os demais países da Europa, América Latina, África, ao ponto de tornar-se uma ameaça à vida da humanidade.

Em um breve percurso, a COVID-19 se desloca de Wuhan para a Coréia do Sul. Da China, a escalada impiedosa da doença chegou à Itália e, de forma desastrosa e assustadora, seus efeitos letais avançaram [e ainda avançam] para Espanha, França e em todos os demais países europeus. Com o poder de alastramento do coronavírus de forma desordenada nos Estados Unidos, especialmente, em Nova York, a doença tem afetado um significativo contingente populacional.

Não diferente, no Brasil, a doença tem avançado por todos os estados brasileiros São Paulo, Rio de Janeiro e Ceará, com os maiores números de casos - promovendo a escalada no alto grau de mortalidade entre as pessoas.

A evolução da ciência ainda não deu conta de impedir de forma rápida a proliferação do vírus com testagens em massa e resposta na produção de tratamento e vacinas. Decerto que, o contágio e a disseminação do vírus passam por mutações diferentes das transmissões anteriores e, da mesma forma, não se tem o domínio do tempo que pode durar tudo isso, nem quais e quantas pessoas serão afetadas ${ }^{17}$ no mundo.

De acordo com a Publicação das Organizações das Nações Unidas Brasil (2020), a Organização Mundial da Saúde (OMS) e a União Internacional de Telecomunicações (UIT) uniram forças para trabalhar juntas, envolvendo empresas de telecomunicações com o propósito de enviar mensagens de texto com informações de saúde, com o objetivo de, neste momento pandêmico, orientar as pessoas com informações sobre a COVID-19.

A referida publicação da ONU Brasil também ressalta que a COVID-19 é a primeira pandemia da história onde a tecnologia e as mídias sociais estão sendo usadas em escala para manter as pessoas seguras, produtivas e conectadas. Aponta que os profissionais de saúde

\footnotetext{
${ }^{17}$ Embora se fale em grupos de risco, o grau de letalidade da doença tem variado de localidade geográfica, de país para país.
} 
estão utilizando a telemedicina para diagnosticar pacientes, e os hospitais estão conectados para coordená-los, e ainda destaca o compromisso da OMS e da UIT no dimensionamento de melhores soluções em saúde digital baseadas nas evidências do crescimento e uso de tecnologias importantes, como a inteligência artificial, no diagnóstico e prevenção dos surtos pandêmicos. (ORGANIZAÇÃO DAS NAÇÕES UNIDAS BRASIL, 2020).

Na perspectiva do capital e da vida humana, Harvey (2020, p. 18) nos coloca a questão de que "o COVID-19 é a vingança da natureza por mais de quarenta anos de maus-tratos grosseiros e abusivos da natureza sob a tutela de um extrativismo neoliberal e desregulado".

A afirmação trazida por Harvey (2020, p. 18) aponta para os avanços e os efeitos do capital, sobretudo, das grandes indústrias - incluindo a área da saúde - que, sistematicamente, priorizam o crescimento e rentabilidade do lucro em detrimento à vida humana. A submissão aos interesses privados tem contribuído para que, as bases essenciais e necessárias à cidadania sejam afetadas, o que reforça ainda mais a expansão desordenada da pandemia.

E em função de todo este tempo de ações deliberadas de degradação ambiental, plenamente voltada para o desenvolvimento do capital, como foco na exploração desmedida sobre este ambiente, podemos dizer que o universo precisou parar para descansar. Essa tem sido exatamente a sensação que paira entre todas as comunidades ao redor do mundo, que a Terra parou. E considerando todas as contradições que estas palavras podem propiciar, em especial, pelos impactos sociais que têm provocado em suas várias dimensões, a parada do universo pode ser interpretada como positiva, à medida que está promovendo significativas reflexões que poderão gerar, no pós-COVID-19, mudanças expressivas sobre como a humanidade poderá estabelecer uma melhor relação entre o mundo e todas as riquezas que nos são oferecidas.

\section{O “NOVO" NA METAMORFOSE DO CAPITAL E DA VIDA HUMANA}

\footnotetext{
“Mas não bastará; também é preciso envolver-se na busca de uma nova prática social que ajude o ser humano a inserir-se na sociedade de maneira ativa e como elemento de transformação". (IMBERNON, 2000, p. 94).
}

O tão esperado século XXI chegou carregado de incertezas e dúvidas, ansiedade e dilemas que estariam pretensamente resolvidos ou, então, que teríamos as respostas para 
diversas questões individuais e coletivas da vida humana: avanços da ciência, da biologia, da genética e da engenharia; progressos digitais, tecnológicos, midiáticos e comunicacionais; respeito às diferenças, participação e cidadania.

Ao mesmo tempo, esperávamos encontrar soluções para as problemáticas não previsíveis existentes: econômicas; ambientais; educacionais; culturais e, principalmente, sociais. Assim, as contradições do capitalismo global representados num movimento em espiral, tanto de expansão e crescimento desenfreado da economia e seus efeitos na vida humana, possibilitam-nos analisar e entender através "das lentes das rivalidades geopolíticas, dos desenvolvimentos geográficos desiguais, das instituições financeiras, das políticas estatais, das reconfigurações tecnológicas e da teia em constante mudança das divisões do trabalho e das relações sociais". (HARVEY, 2020, p. 13)

Fomos surpreendidos com as falhas que não foram corrigidas e que permanecem no novo século e perduram ainda hoje! Assim, consideramos os avanços e progressos, em grande parte, revestidos por severos retrocessos nos quais carregamos, por não conseguirmos: reduzir as desigualdades econômicas e sociais; erradicar a pobreza e a miséria; solucionar as mazelas do analfabetismo e da falta de escolarização; reconhecer o direito às diferenças culturais individuais e coletivas; aprender a valorizar as experiências da maturidade e da velhice; superar o preconceito e o racismo estrutural de várias ordens - racial, homofóbico, transfóbico, gordofóbico e tantos outros radicalismos transformados em ódio; bem como vencer a barbárie do feminicídio, genocídio, intolerância religiosa, que ainda marcam as culturas de nossos tempos.

Não nos surpreende dizer que a pandemia é passageira e provisória. Mas, enquanto não passar, deixará fortes marcas na sociedade mundial. Não podemos dizer o mesmo sobre a crise financeira permanente que nos dá mostras de enfraquecimento nos investimentos em áreas tratadas como estratégicas e urgentes para a garantia de sobrevivência de parte significativa da humanidade, no caso, das políticas de saúde e das políticas sociais.

Ao que parece, estamos diante de uma lente aumentada das fragilidades dos sistemas de saúde que, mesmo conhecidas até certo modo, agora estão mais próximas da massiva população, sobretudo, quando constatamos a falta de hospitais com respiradores, equipamentos de proteção individual para as equipes de saúde, leitos para a população, serviços de testagem etc. Não por acaso, a desigualdade social e as desvantagens econômicas apontadas na área da saúde recaem sobre as políticas sociais, a exemplo da vulnerabilidade 
deixada entre as populações pobres ou que estão em pobreza extrema, pela escassez na oferta de água, saneamento, higiene pela falta de acesso a bens materiais, cujo Estado deve ser o garantidor da proteção ao contingente mais vulnerável.

Na contradição, deparamo-nos com a existência permanente de um distanciamento social que, sob a perspectiva da desigualdade econômica e concentração de riqueza nas mãos de poucos, antecede à pandemia do coronavírus. Daí, podemos dizer que a ampliação da pobreza e da extrema pobreza disseminada e distribuída entre a população mundial torna invisíveis os milhões de brasileiros que buscam, nas políticas sociais, uma dupla garantia mínima: a proteção social, por meio de subsídios emergenciais do Estado e a proteção à saúde, por meio de políticas de assistência.

Ao passo que, o isolamento social, na perspectiva do alcance das políticas econômicas e sociais aos mais pobres e frágeis, reforça o apagamento das comunidades afastadas que estão distantes dos centros urbanos, a exemplo dos ribeirinhos, das comunidades rurais, indígenas, quilombolas, que enfrentam mais dificuldades de acesso aos programas emergenciais de assistência.

Interrogamos que as expressões "isolamento social", "quarentena", "fique em casa", "distanciamento social", "uso contínuo de máscaras e álcool em gel”, estão direcionadas para quem? O que revelam para o imenso contingente da população?

Em tempos de pandemia, a situação social e financeira, no âmbito das relações de trabalho e renda agrava-se mais, quando constatamos que parte significativa dos trabalhadores não consegue exercer as suas atividades em casa (home office). Nesse contexto, antes mesmo da pandemia, acumulávamos cerca de 11,6 milhões de desempregados ${ }^{18}$, o que representam $10,6 \%$ da população. Somando ao quantitativo de desalentados ${ }^{19}$, chegamos, aproximadamente, a 4,6 milhões de pessoas. Sem falar no número crescente de trabalhadores informais no Brasil que, em 2019, alcançou algo em torno de 38,8 milhões, o que representa a média de 41,4\% dos que se declaram ocupados, segundo dados do IBGE 2019.

\footnotetext{
18 Vale dizer que, segundo o IBGE, desempregados significa "às pessoas, com idade para trabalhar (acima de 14 anos) que não estão trabalhando, mas estão disponíveis e tentam encontrar trabalho". No caso, não são considerados: universitários com dedicação somente aos estudos, dona de casa que não trabalha fora, nem empreendedores que possuem seu próprio negócio. Disponível em: www.ibge.gov.br. Acesso em: 02 jun. 2020. ${ }^{19} \mathrm{O}$ desalento representa os que desistiram de procurar emprego. Disponível em: www.ibge.gov.br. Acesso em: 02 jun. 2020.
} 
Arriscamos dizer que, para muitos, o isolamento social torna-se um desejo e não reflete a situação da maioria dos trabalhadores, principalmente, os mais empobrecidos que não usufruem das mesmas condições de cuidado e proteção.

De acordo com a publicação da Confederação Nacional de Serviços - CNS (2020), o fato de se ter uma projeção de um número muito elevado de mortes na China e Itália levaram seus governos a adotarem medidas extremas de controle da propagação do vírus, com severas restrições à mobilidade das pessoas. Nesse sentido, a CNS (2020) propôs algumas medidas e orientações que têm sido seguidas por vários países, o que tem comprometido com impactos severos nas economias ao redor do mundo.

Com base nestas projeções, alguns governos apontam para o enfrentamento da pandemia definindo medidas de austeridade, incluindo cortes nas despesas públicas, que geram resultados expressivos nos diversos setores da sociedade.

A CNS (2020) afirma, ainda, que ao contrário das crises econômicas clássicas, que se iniciam com a deterioração dos fundamentos que dão estabilidade às economias nacionais, a crise atual se origina nas reduções drásticas de demanda por produtos e serviços e da produção de bens nas regiões afetadas pela epidemia. Por se tratar de uma pandemia, o impacto é global.

O desafio de conter a pandemia e reduzir os riscos impõe ao Estado o dever de suprir os mais vulneráveis com mecanismos de intervenção e apoiar com políticas sociais emergenciais. Enquanto essas políticas sociais intervencionistas não acontecem, as populações humanas secundarizam a tudo e manifestam comportamentos que mais aumentam os riscos de contágio e a proliferação do coronavírus. Nas palavras de Harvey (2020, p. 16), "o impacto econômico e demográfico da disseminação do vírus depende de fissuras e vulnerabilidades preexistentes no modelo econômico hegemônico".

Em parte, as fissuras nas relações sociais, na lógica do capital, dão sinais de intensificação da produtividade e na acumulação de riqueza. Dessa maneira, estamos diante de um dos maiores desafios: subverter a máxima do lucro e poder do dinheiro pela causa humana como fundamentais nesse processo em que, seguramente, a contenção do avanço da doença e redução da letalidade passa pelo controle e menor circulação de pessoas nas ruas, 
sobretudo àquelas consideradas como grupo de risco $^{20}$ pela Organização Mundial da Saúde (OMS).

Observamos que os efeitos econômicos em descontrole têm gerado uma forte ruptura das cadeias produtivas que, de forma direta, retardaram e reduziram a produção, dando mostras de seus efeitos na mão de obra e nos impactos no mercado de trabalho, ou seja, nas demissões e na retração de trabalhadores nas áreas da agricultura, comércio, indústria e serviços.

Sob forte campanha, o lema "Fique em casa!" tem marcado o isolamento social como uma estratégia de redução da proliferação do vírus, por meio de Decreto da Presidência, que estabelece aos estados e municípios, os serviços públicos e as atividades consideradas essenciais para funcionamento ${ }^{21}$. Forçosamente ou não, áreas como: educação; repartições públicas; empresas de tecnologias e áreas administrativas conseguem de forma remota, dar continuidade às atividades profissionais e manter o processo produtivo.

No interior dessa campanha, o que se revela é a divisão social e técnica do trabalho que marca e segrega, principalmente, os trabalhadores informais e prestadores de serviço. As evidências da desigualdade se mostram explícitas entre os que podem ficar em casa dos que não podem; os que correm mais riscos de exposição ao vírus dos que podem cumprir a quarentena isolados; os que estão mais próximos da infecção dos que se mantêm afastados do vírus.

De uma forma geral, o setor de serviços tem sofrido bruscas consequências com a vertiginosa queda na área comercial e de serviços hoteleiros, shoppings, bares e restaurantes, comércio de vestuário, prestação de serviços entre outros. Em contrapartida, assistimos a uma reinvenção de algumas áreas para a economia global, como é o caso dos serviços ligados aos trabalhadores uberizados ${ }^{22}$, serviços delivery de entrega em domicílio de refeições, alimentos, produtos de farmácia etc.

\footnotetext{
20 Para a Organização Mundial de Saúde (OMS), caracteriza-se como grupo de risco: idosos, diabéticos, hipertensos, pessoas com insuficiência renal crônica, doença respiratória crônica e doença cardiovascular.

${ }^{21}$ O Decreto № 10.282/2020 regulamenta a Lei no 13.979/2020, para definir os serviços públicos e as atividades essenciais. No caso, são serviços públicos e atividades essenciais aqueles indispensáveis ao atendimento das necessidades inadiáveis da comunidade, assim considerados aqueles que, se não atendidos, colocam em perigo a sobrevivência, a saúde ou a segurança da população. (BRASIL, 2020).

${ }^{22} \mathrm{Na}$ contemporaneidade, a "uberização" do trabalho se refere às novas formas de exploração e precarização das relações qualitativas ao trabalhador.
} 
No plano econômico, em que estão presentes as relações sociais capitalistas, identificamos que a COVID-19 tem cor, raça, sexo e classe social. Se as políticas econômicas e financeiras precedem das relações humanas, eis que o mercado se torna o "instrumento eficaz para regular os interesses e as relações sociais de forma 'livre, equânime, equilibrada e justa"”. (FRIGOTTO, 2007, p. 83)

É sempre bom lembrar que o Estado capitalista se encarrega de educar e convencer de forma imperceptível. Consciente ou inconsciente, o convencimento e o consentimento das massas penetram na vontade ideológica, na vontade política e coletiva. Dito de outra forma, os trabalhadores que são os maiores afetados pela situação econômica, a priori, não percebem o papel do Estado em proteger e garantir programas assistenciais urgentes, nem o quão proposital que é a diluição da luta e do encorajamento político nas disputas por participação e engajamento, enquanto garantias democráticas de proteção à saúde e vida humana.

De tudo, o percurso do coronavírus não poderá ser maior do que a nossa vontade de combatê-lo! Nesse sentido, acumulamos muitos exemplos de superação em ações e expressões de reinvenção, inovação e novas alternativas dinâmicas de trabalho e consumo, inseridos no processo humanitário e de cidadania.

\section{NOVOS TEMPOS DE SOLIDARIEDADE, FORMAÇÃO HUMANA E CIDADANIA}

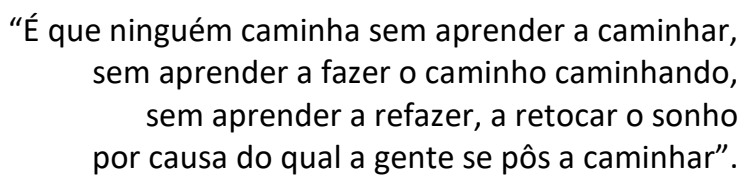

(FREIRE, 1992, p. 155).

$\mathrm{O}$ ataque devastador de um vírus invisível tem levado a população mundial às mudanças nas atitudes, comportamentos e valores, em um movimento de "consciência de comunhão planetária, de algum modo democrática", como nos presenteia Boaventura de Sousa Santos (2020, p. 8), em sua publicação mais recente sobre a pandemia do coronavírus.

Nesse sentido, o processo transgeracional tem nos mostrado as diferentes mudanças e rupturas do passado, o que significa hábitos sociais que estão se transformando de acordo com a nova dinâmica cultural. Em outras palavras, a ruptura de hábitos sociais, apreendidos 
nos moldes geracionais da tradição familiar, continua a ser parte dos saberes herdados, dos princípios apreendidos e da própria imitação nas referências de família.

Em parte, isso explica as influências adquiridas com os membros da família, da comunidade, da vizinhança, revelados nos comportamentos morais, hábitos, valores, princípios, culturas que passaram a ser questionadas sobre o porquê de continuarmos agindo dessa ou daquela maneira.

Algumas normas caem, enquanto outras são adaptadas e transformadas, o que significa que as tradições sofrem as mutações aos novos tempos. Lembremo-nos que os sistemas educativos são os que mais recebem as diferenças em seus espaços abertos das salas de aula.

Assim vivemos "novos tempos" em que normas, os princípios e valores sociais, culturais e, sobretudo, humanos estão sendo colocados à prova nessa pandemia que invade o mundo. No caso, os sistemas educativos têm empreendido novas funções, seja resgatando "velhos" comportamentos, critérios e normas; seja discutindo alguns "novos" outros. Curiosamente, em um contexto de educação para um novo século, recorremos à Subirats (2000, p. 202), que defende uma mudança de sentido que envolva "um debate social sobre a natureza de uma nova moral, que já não pode ser de conteúdo, mas de critérios".

Nesse novo projeto humanista que está em curso, não há lugar para a competição e acumulação de riquezas e bens, pois vimos o aumento da desigualdade e das ameaças à natureza humana. Com o surto do coronavírus, motivos não faltam para repensarmos alternativas educativas e humanas para continuarmos a bem viver ainda neste século.

O consumismo excessivo na contemporaneidade deu lugar à degradação ambiental pela circulação desenfreada de voos, transportes poluidores e emissões desmedidas de gases geradores do efeito estufa. Entre os efeitos positivos da paralisia do mundo, já podemos assistir e constatar a diminuição da poluição atmosférica com a melhoria da qualidade do ar e, em curto prazo, a natureza viva na fauna e na flora, que começam a se reestabelecer.

Algumas lições estão em fase de adoção na vida cotidiana da população mundial em um curto tempo, levada a superar modos de vida que não são suficientes de continuarem existindo. É dessa forma que Freitas (2020) reforça a análise sobre o esgotamento e a substituição do capitalismo, aliada ao enfraquecimento das relações sociais, quando nos mostra, em recente comunicação em seu blog, que "esta é a mensagem básica do vírus: o atual modo de vida predatório está esgotado". 
Já não há mais lugar para a perpetuação do existente (Meszáros, 2005), pois chegamos ao ponto de repensar a razão perversa e a promover, em nós e em "nós-outros" a mudança nas relações desumanas. Como sinônimo, têm aflorado nas populações do mundo o sentido e o sentimento de solidariedade, a preocupação com os cuidados individuais e coletivos nas vizinhanças, comunidades, grupos sociais e redes de ajuda mútua.

Das causas humanitárias, vemos a sensibilização de diferentes grupos societários e multinacionais, envolvendo empresários de níveis e de ramos diversos às pessoas comuns e nos deparamos com redes de solidariedade aos idosos, moradores de rua e pessoas consideradas mais vulneráveis aos riscos da doença. Eventos religiosos, musicais, esportivos, culturais, disponibilizados nas redes sociais e de computadores espalhados pelo mundo, têm dado nova direção e rumo aos "contatos" tecnológicos, comunicacionais e midiáticos da geração do presente.

Sem falar na adesão dos sistemas de ensino às práticas pedagógicas, formais e não formais, de aulas online, por meio das ferramentas e recursos da internet, caracterizando novas formas de ensinar e aprender. Referimo-nos a um formato tímido de educação à distância por acompanharmos os debates e as discussões acerca das controvérsias nos atuais modelos de atividades online, encontros e aulas nas plataformas digitais.

De todo modo, esperamos que a trajetória dura que temos vivido sirva de aprendizado para revermos e refazermos ações, posturas, comportamentos, princípios e valores capazes de nos tornar melhores. E, por fim, que o nascimento do "novo" homem encarnado em nós, possa fluir na essência, para o começo de um novo tempo.

\section{CONSIDERAÇÕES FINAIS}

"A nossa fé é a vacina!" (Cordel “A Quarentena”, de Moraes Moreira ${ }^{23}$ )

Em um momento no qual o mundo se obriga a pensar os rumos da humanidade no presente e no futuro, temos a chance de escrever sobre uma realidade devastadora - em andamento - pelo surto da pandemia causada por um vírus invisível com grande poder de avanço, em descontrole, entre as populações.

\footnotetext{
${ }^{23}$ Moraes Moreira faleceu no período da pandemia, em 13 abr. 2020. (MORAES..., 2020). 
A pandemia da COVID-19 deixará nas gerações que ficam e, sobretudo, nas mais jovens, recordações de uma trajetória movida pela necessidade de repensar os modos de vida no capitalismo. Isso mostra que os sentimentos e os valores que dão vida à existência humana - a solidariedade, os cuidados individuais e coletivos, a preservação da saúde física e mental, a sustentabilidade ambiental, a conservação dos bens da natureza entre outros - precisam ser entendidos como prioridade, em detrimento dos negócios e dos bens estruturais e materiais.

Temos percebido que a forma como vemos as coisas, em meio ao combate desse vírus tão complexo, está diferente, embora reconheçamos que somos os mesmos. A mudança no olhar tem sido inevitável! É assim que Santos $(2020$, p. 5) nos permite ler o mundo de forma sublime, pois "a crise é, por natureza, excepcional e passageira, e constitui a oportunidade para ser superada e dar origem a um melhor estado de coisas".

Nisso tudo, o sentido de comunidade tem conduzido a certeza de que há esperança. Então, a causa humanitária tem mobilizado mais as pessoas que, juntas e ao mesmo tempo separadas, estão dispostas a construir em uma rede de apoio aos mais vulneráveis, aos que não podem cumprir o isolamento social, incluindo os que estão na linha de frente de combate ao coronavírus, como os profissionais da área da saúde.

Em tempos difíceis que assombram o mundo, vemos como uma oportunidade do reencontro com nossos valores, princípios e sentimentos que afloram em cada um. Então, repensemos que o isolamento e o distanciamento social servem para preservarmos a saúde física como bem mais preciso e não de afastamento afetivo em gestos de carinho, amor e solidariedade.

Em certa medida, a escrita esperançosa e futurista não se esgota aqui, pois estamos construindo uma nova história e uma nova ordem social de alcance mais democrático e mais igualitário.

\section{REFERÊNCIAS}

BRASIL. Decreto № 10.282, de 20 de março de 2020. Regulamenta a Lei no 13.979, de 6 de fevereiro de 2020, para definir os serviços públicos e as atividades essenciais. Diário Oficial da União: seção 1: extra, Brasília, DF, 21 abr. 2020. Disponível em: http://www.in.gov.br/en/web/dou/-/republicacao-249098206. Acesso em: 02 jun. 2020. 
FREIRE, Paulo. Pedagogia da Esperança: um reencontro com a pedagogia do oprimido. Rio de Janeiro: Paz e Terra, 1992.

FREITAS, Luiz Carlos de. A mensagem do vírus. In: FREITAS, Luiz Carlos de. Avaliação Educacional: Blog do Freitas. [S. I.], 29 mar. 2020. Disponível em: https://avaliacaoeducacional.com/2020/03/29/a-mensagem-do-virus/. Acesso em: 02 jun. 2020.

FRIGOTTO, Gaudêncio. Os delírios da razão: crise do capital e metamorfose conceitual no campo educacional. In: GENTILI, Pablo (org.). Pedagogia da exclusão: o neoliberalismo e a crise da escola pública. Petrópolis, RJ: Vozes, 2007. p. 77-108.

GRAFFITI em Hong Kong: "Não podemos voltar ao normal, porque o que era normal era exatamente o problema." (Vi na newsletter do @ICALondon). [S. I.], 28 mar. 2020. Twitter: @ricksenra. Disponível em: https://twitter.com/ricksenra/status/1243922547621707776. Acesso em: 02 jun. 2020.

HARVEY, David. Política anticapitalista em tempos de COVID-19. In: DAVIS, Mike et al. Coronavírus e a luta de classes. Brasil: Terra sem Amos, 2020. p. 13-23.

IMBERNON, Francisco. A educação no século XXI: os desafios do futuro imediato. Porto Alegre: Artes Médicas Sul, 2000.

GIDDENS, Anthony. 0 mundo em descontrole. Rio de Janeiro: Record, 2003.

MESZÁROS, István. A educação para além do capital. São Paulo: Boitempo, 2005.

MORAES Moreira publicou cordel sobre os medos da pandemia; leia. Uol, São Paulo, 13 abr. 2020. Entretê. Música. Além da matéria é disponibilizado na íntegra o cordel "A Quarentena", de Moraes Moreira. Disponível em: entretenimento.uol.com.br/noticias/redacao/2020/04/13/moraes-moreira-publicou-cordelsobre-os-medos-da-pandemia-leia.htm. Acesso em: 19 abr. 2020.

ORGANIZAÇÃO DAS NAÇÕES UNIDAS BRASIL. OMS e UIT trabalham com empresas de telecom para enviar informações de saúde por SMS. [S. l], 24 abr. 2020. Disponível em: https://nacoesunidas.org/oms-e-uit-trabalham-com-empresas-de-telecom-para-enviarinformacoes-de-saude-por-sms/. Acesso em: 02 jun. 2020.

SANTOS, Boaventura de Sousa. A cruel Pedagogia do Vírus. Coimbra, PT: Edições Almedina, 2020. 
SUBIRATS, Marina. A educação do século XXI: a urgência de uma educação moral. In: IMBERNON, Francisco (org.). A educação no século XXI: os desafios do futuro imediato. Porto Alegre: Artes Médicas Sul, 2000. p. 195-204.

Recebido em 27/04/2020

Aceito em 03/06/2020 